\title{
Natural History of Alcoholic Hepatitis
}

\author{
IV. GLYCOSAMINOGLYCURONANS AND COLLAGEN
}

IN THE HEPATIC CONNECTIVE TISSUE

\author{
John T. Galambos and Raymond ShapiRa \\ From the Division of Digestive Diseases, Department of Medicine and \\ Department of Biochemistry, Emory University School of Medicine and Grady \\ Memorial Hospital and Emory University Hospital, Atlanta, Georgia 30303
}

A в S T R A C T The extractable and nonextractable collagen and glycosaminoglycuronans (GAG) were estimated and characterized in 32 dried, defatted human livers obtained at necropsy. 10 had normal livers. 22 of the 32 livers were from patients who drank in excess: 5 had fatty livers, 7 had alcholic hepatitis, and 10 had cirrhosis. Livers with alcoholic hepatitis or cirrhosis had significantly increased total and $1 \mathrm{~N} \mathrm{NaCl}$-extractable collagen. Only alcoholic hepatitis livers had significantly increased Tris-buffer-extractable GAG, but the amino acid composition of these GAG (proteoglycans) was no different from that of normal livers. The major fraction of these GAG had isoelectric $\mathrm{pH}(\mathrm{pI}) \leq 3.1$ in all livers. Livers with alcoholic hepatitis or cirrhosis had significantly increased nonextractable GAG. The major GAG fraction of all livers was chondroitin-4 or -6-SO4. Alcoholic hepatitis livers had a significant increase of hyaluronic acid and an unidentified hyaluronidase-resistant GAG. Fatty livers showed no differences from normal ones.

The data indicates that alcoholic hepatitis is associated with a significantly increased fibroblast activity, but fatty livers of alcoholics are not. The changes in histologically "inactive" micronodular cirrhosis of alcoholic patients indicate continued activity of fibroblasts in the connective tissue of these cirrhotic livers.

\section{INTRODUCTION}

The pathogenesis of cirrhosis in alcoholics was thought to have been related to fatty changes in the liver, but recently alcoholic hepatitis has been recognized as a precursor of cirrhosis (1). Only a proportion of ex-

Received for publication 13 February 1973 and in revised form 6 July 1973. tensive drinkers develop cirrhosis. The reason for the progression of ethanol-induced liver injury to cirrhosis may be related to the response of hepatic fibroblasts to injury (2). This suggestion is supported by the demonstrated differences of growth characteristics of hepatic fibroblasts in tissue culture grown from biopsies of alcoholic hepatitis livers as opposed to normal or fatty livers (3). Recent observations suggest that the development of cirrhosis may be related to direct induction of hepatic fibroblasts by ethanol (4) or to their induction by ethanol-induced parenchymal injury. Increased activity of hepatic fibroblasts is manifested by formation of collagen fibers and extracellular ground substance. An intimate relationship between glycosaminoglycuronans $(\mathrm{GAG})^{1}$ of the ground substance and fiber formation has been described $(5,6)$. The induced fibroblast may produce excessive amounts of GAG, which may or may not be hydrolyzed by lysosomal hyaluronidase $(5,7)$. The present study was undertaken to determine the collagen and GAG concentrations and compositions in normal, fatty, alcoholic hepatitis, and cirrhotic livers.

\section{METHODS}

Livers were obtained at autopsy from 10 nonalcoholic patients who had no liver disease and from 22 alcoholic patients with 3 types of liver injury: 5 had fatty liver, 7 had alcoholic hepatitis and 10 had cirrhosis. Patients with fatty liver died from causes unrelated to liver disease: three with trauma, one with pneumonia, and one with alcoholic delirium. Patients with alcoholic hepatitis had progressive and severe parenchymal hepatic failure. Patients with cirrhosis died of complications of their disease: three had

${ }^{1}$ Abbreviations used in this paper: CPC, cetylpyridinium chloride; DDL, dried defatted human liver powder; GAG, glycosaminoglycuronans; $\mathrm{HO}-\mathrm{Pr}$, hydroxyproline; $\mathrm{pI}$, isoelectric $\mathrm{pH} ; \mathrm{PMN}$, polymorphonuclear. 
gastrointestinal bleeding, three with hepatorenal syndrome, two with infection, one with coma, and one with trauma. Autopsies were performed within 1-5 h after death. There was no relationship between the delay of autopsy and the four diagnostic categories. Livers were fixed in $4 \%$ formaldehyde and histologic examinations were done on hematoxylin-eosin, Mallory's aniline blue, alcian blue-periodic acid-Schiff, and van Gieson-stained sections. The case was excluded from the study if postmortem autolysis was seen. The following diagnostic criteria were used: normal, either no histopathology or only passive congestion was seen; steatosis, $\geq 50 \%$ of hepatocytes contained fatty vacuoles and only minimal or no necrosis or inflammation was seen; alcoholic hepatitis, the morphologic criteria for the diagnosis were previously described in detail (8). Briefly, the diagnosis of alcoholic hepatitis required portal edema and inflammation with invasion of the limiting plate, a zonal hepatocellular necrosis involving at least zone 3 of the hepatic acinus of Rappaport (9) and a predominantly polymorphonuclear (PMN)-leukocytic inflammatory exudate. Because this type of alcoholic injury characteristically af fected zone 3 of the hepatic acinus, degenerating, ballooned hepatocytes, parenchymal necrosis, and edema were most prominent around the efferent ("central") vein. This process resulted in compression of this vein, and often it could no longer be identified. The ballooned hepatocytes contained weblike cytoplasmic remnants and eosinophilic clumps of various shapes. In some liver, groups of these enlarged hepatocytes contained alcoholic hyalin but the typical hyalin was not seen in every liver. PMN leukocytes were usually seen within or around these enlarged, degenerating hepatocytes or in areas of necrosis. Steatosis was seen in each of the livers included in this study. The livers with alcoholic hepatitis contained intralobular and periportal fibrosis, but fibrous septums and nodular regeneration were not seen. Cirrhosis: septa and nodules were well developed but only minimal parenchymal necrosis and inflammation were present. Those livers containing both cirrhosis and significant alcoholic hepatitis were excluded from this study.

The livers were cut in about $\frac{1}{2}-\mathrm{cm}$ thin slices, sectioned to $2-5-\mathrm{cm}$ strips and put in acetone. The containers were agitated to prevent adherence of fragments. The strips of fixed liver tissue were meticulously dissected free from capsular, vascular, and other visible extraneous connective tissue. Care was taken not to remove fibrous septa of cirrhotic livers, but all visible blood vessels were stripped off the tissues. (These structures were removed and discarded because their GAG content could have contaminated hepatic GAG). The fragments of liver were homogenized and were repeatedly extracted with acetone, with acetone-ether, and with ether. The dried defatted liver powder (DDL) was
TABLE I

\begin{tabular}{lrr}
\hline \multicolumn{1}{c}{ Diagnosis } & $\begin{array}{c}\text { Number } \\
\text { of } \\
\text { livers }\end{array}$ & DDL \\
\hline & & $g$ \\
Normal $^{*}$ & 10 & 210 \\
Fatty liver $\ddagger$ & 5 & 85 \\
Alcoholic hepatitis & 7 & 270 \\
Cirrhosis & 10 & 220 \\
\hline
\end{tabular}

* 6 of the 10 had passive congestion due to heart failure.

$\ddagger$ Over $50 \%$ of hepatocytes of these chronic alcoholics were distended with fat.

The diagnosis of alcoholic hepatitis or cirrhosis was made according to the morphologic criteria described previously (8). Two of the livers with alcoholic hepatitis had early septum formation and five had intralobular fibrosis on histologic examination.

stored in sealed plastic bags in a desiccator at $4^{\circ} \mathrm{C}$ until it was used.

Hepatic collagen. $10 \mathrm{mg}$ of the DDL was hydrolyzed in vacuum-sealed vials in $6 \mathrm{~N} \mathrm{HCl}$ at $120^{\circ} \mathrm{C}$ for $18 \mathrm{~h}$ for determination of total hydroxyproline (HO-Pr) ; $100 \mathrm{mg}$ of liver powder was used for the determination of $1 \mathrm{~N}$ $\mathrm{NaCl}$-extractable HO-Pr (10-12).

$G A G$. The number of cases in each diagnostic category and the total amount of DDL used in each are listed in Table I. At least $20 \mathrm{~g}$ of DDL were used from each normal and cirrhotic liver, 15 or $20 \mathrm{~g}$ of DDL from each fatty liver, and 30 or $40 \mathrm{~g}$ of DDL from each alcoholic hepatitis liver.

Extractable GAG and proteoglycans. Because the native state of GAG in connective tissue is probably proteinpolysaccharide macromolecules (proteoglycans), gentle extraction procedures were used to keep their degradation to a minimum. Proteoglycans are one of the largest negatively charged macromolecules in mammalian tissue; therefore, their isolation was based on these two properties: low isoelectric point ( $\mathrm{pI}$ ) and large size. In the liver the concentration of proteoglycans and GAG is low and these are extracted with much larger amounts of proteins and glycoproteins. Complex and prolonged procedures were required to separate the proteoglycans from contaminating glycoproteins. All procedures were done on replicates.

\section{Extraction. $\quad 0.05 \mathrm{M}$ Tris/0.38 M Glycine $\mathrm{pH} 8.2100 \mathrm{ml} / 5 \mathrm{~g} \mathrm{DDL}^{2}$ stirred in VirTis ${ }^{3}$}

for $30 \mathrm{~min}$ at $0^{\circ}$ with magnetic stirrer for $18 \mathrm{~h}$ at $4^{\circ} \mathrm{C}$

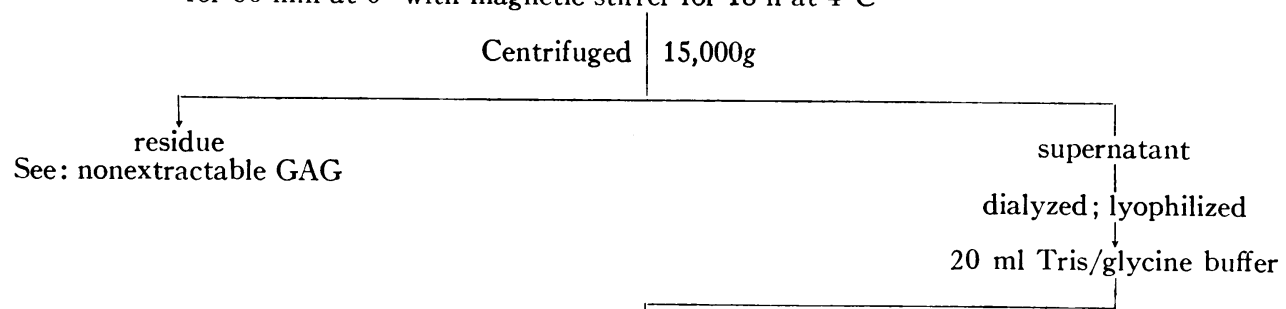

${ }^{2}$ The fibrous fragments of cirrhotic liver were included in the DDL.

${ }^{3}$ VirTis Co., Inc., Gardiner, N. Y. 
Electrophoretic purification.

continuous flow electrophoresis (13) at $4^{\circ} \mathrm{C}$

$\begin{aligned} & \text { continuous flow electrophoresis (13) at } 4^{\circ} \mathrm{C} \\ & \text { anodic half }\end{aligned}$
proteins; discarded

Electrofocused in Ampholine pH 3-6 gradient on LKB $1801^{4}$ at $200 \mathrm{~V}$ for $72 \mathrm{~h}$

remainder

anodic peak

only proteins; discarded

made $0.5 \mathrm{~N} \mathrm{NaCl}$

dialyzed; lyophilized

Estimation of total extractable GAG/5 or $10 \mathrm{~g} D D L$ from each liver.

Dissolved in $5 \mathrm{ml} \mathrm{H}_{2} \mathrm{O}$ and hexuronic acids were measured by the modified carbazole reaction (14)

$\frac{4}{5}$ of each were pooled according to the four giagnostic categories and were lyophilized.

Separation of proteoglycans from $G A G$.

$$
\begin{array}{l|l}
5 \times 120 \mathrm{~cm} & \begin{array}{l}
\text { Eluted in N NaCl} \\
\text { Sephadex G 150 }
\end{array} \\
\text { at } 12^{\circ} \mathrm{C}
\end{array}
$$

Retained in gel

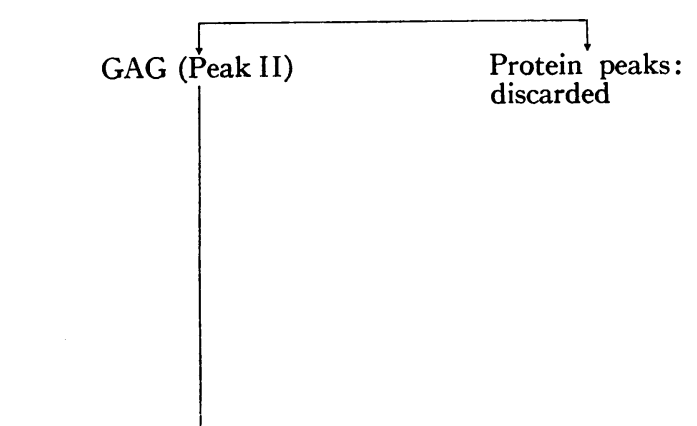

Excluded volume (Peak I) Dialyzed $4^{\circ} \mathrm{C}$ lyophilized

Electrofocused in Ampholine pH 3-10 gradient on KLB 1801 at $400 \mathrm{~V}$ for $52-54 \mathrm{~h}$ at $8^{\circ} \mathrm{C}$

Fraction collected $0.33 \mathrm{ml} / \mathrm{min}$ measured $\mathrm{pH}$ of each $1 \mathrm{ml}$

Pooled proteoglycans according to isoelectric $\mathrm{pH}(\mathrm{pI})$ (Fig. 1)

Digested in $\downarrow$ papain and pronase

Characterization of extractable GAG according to Calatroni and diFerrante (15).

?

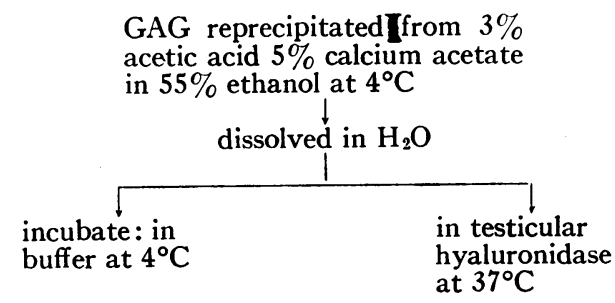

${ }^{4}$ Laboratorie Och Kemikaliska Produkter, Stockholm, Sweden. 


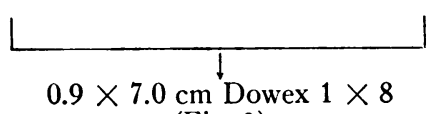

$0.9 \times 7.0 \mathrm{~cm}$ Dowex $1 \times 8$

(Fig. 2)

Eluted with increasing $\mathrm{NaCl}$ concentrations, each fraction was precipitated in $70 \%$ ethanol dissolved in water, and

GAG were estimated by the carbazole reaction (14).

Recoveries. Because of contaminating proteins, the carbazole reaction (14) did not give reliable values on the original extracts but did so after the initial electrophoretic purifications. $80-105 \%$ of "total absorbency" of the carbazole color was recovered from Sephadex G-150 chromatography and $88-109 \%$ after electrofocusing. The recovery averaged $74 \%$ when purified proteoglycans $(16,17)$ from bovine nasal cartilage were carried through the procedure.

The amino acid composition of the proteoglycans was determined by the method of Malawista and Schubert (16), as modified by Heinegard and Gardell (17). Pooled representative samples were assayed from fractions excluded from Sephadex G-150 (Peak I) and had pI $\leq 3.1$ from normal and from alcoholic hepatitis livers.

\section{Nonextractable GAG}

Preliminary purification. Residues of Tris/glycine extracts were digested by papain, were incubated at $4^{\circ} \mathrm{C}$ in $0.5 \mathrm{~N} \mathrm{NaOH}$ in $0.05 \mathrm{~N} \mathrm{NaBH}_{4}$ (18), and were precipitated in $10 \%$ trichloracetic acid

$\begin{array}{ll}\text { Precipitate, discarded } & \begin{array}{l}\text { Supernate and washes were neutralized, dia- } \\ \text { lyzed at } 4^{\circ} \mathrm{C} \text {, and eluted with } \mathrm{H}_{2} \mathrm{O} \text { from } 2.5 \times 20 \\ \mathrm{~cm} \text { Dowex } 50-\mathrm{X} 8(\mathrm{H}+)\end{array} \\ & \text { were dialyzed at } 4^{\circ} \mathrm{C} \text {, lyophilized. }\end{array}$

Estimation of total nonextractable GAG/10 g DDL from each liver. Dissolved in $10 \mathrm{ml} \mathrm{H}_{2} \mathrm{O}$, and hexuronic acids were measured by the modified carbazole reaction (14).

The remaining $9.5 \mathrm{ml}$ was made $3 \%$ acetic acid, $5 \%$ calcium acetate; GAG were fractionated by precipitations in $40 \%$ and $55 \%$ ethanol at $4^{\circ} \mathrm{C}$ according to Meyer, Linker, Davidson, and Weissmann (19).

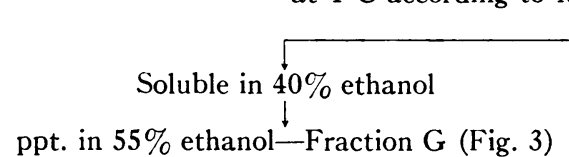

ppt. in $55 \%$ ethanol-Fraction G (Fig. 3)

\footnotetext{
${ }^{5}$ Mesh 120/140 (Gas-Chrom-P) Applied Science Labs., Inc., State College, Pa.
}

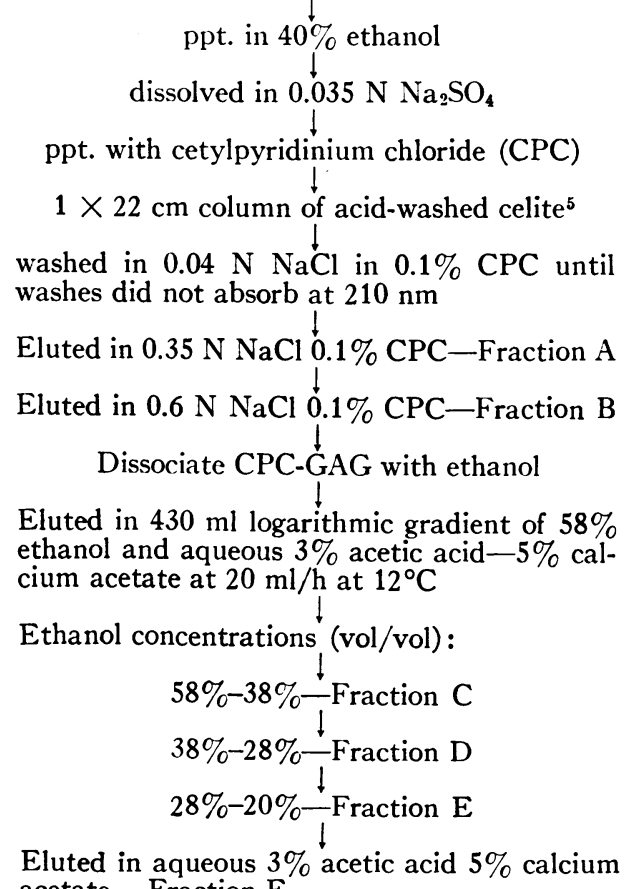

Eluted in aqueous $3 \%$ acetic acid $5 \%$ calcium acetate.-Fraction $\mathrm{F}$ 
After Fraction $F$ further elution of the columns with 2 $\mathrm{N} \mathrm{NaOH}$ did not remove any additional carbozole-reacting material. Replicate analyses from the same liver were within $\pm 10 \%$ of the average estimates of hexuronic acids.

\section{Recovery of GAG in Fractions A-F}

Hyaluronic acid. 91-96\% was in the $0.35 \mathrm{~N} \mathrm{NaCl}$ elution of the CPC precipitate (Fraction A).

Heparan-SO $\mathrm{S}_{4}$ 86-95\% was in the $0.6 \mathrm{~N} \mathrm{NaCl}$ elution of the CPC precipitate (Fraction B).

Chondroitin-6-SO $\mathrm{S}_{4}$ (shark). 81-90\% was in the 58\%$38 \%$ ethanol gradient (Fraction $\mathrm{C}$ ), but none of chondroitin-4-SO (bovine cartilage) was removed by this fraction.

Chondroitin-4-SO $\mathrm{S}_{4}$. 25-40\% was in the $38 \%-28 \%$ ethanol gradient (Fraction D) and $60 \%-75 \%$ in $28 \%-20 \%$ ethanol gradient (Fraction $\mathrm{E}$ ).

Dermatan- $\mathrm{SO}_{4} .92-100 \%$ was in the aqueous $3 \%$ acetic acid $5 \%$ calcium acetate (Fraction F). None was removed in the ethanol gradient.

The replicates of each liver were within $\pm 10 \%$ of the average.

\section{Characterization of GAG in Fractions A-G}

Each fraction was analyzed for hexuronic acid, hexosamines, $\mathrm{SO}_{4}$, hexose, sialiac acid, and fucose and for susceptibility to testicular hyaluronidase. The range of molar ratios of hexosamines and $\mathrm{SO}_{4}$ varied $\pm 14 \%$ among the four diagnostic groups. Duplicates were within $\pm 10 \%$. Assays for $\mathrm{SO}_{4}$ and hyaluronidase digestion were not performed on the following fractions because sufficient amount of material was not available for analysis: normal $C$ and $\mathrm{E}$; fatty liver $\mathrm{A}, \mathrm{B}, \mathrm{F}$, and $\mathrm{G}$.

The GAG fractions $A$ through $G$ were pooled according to the four diagnostic categories. Duplicate samples of each were incubated in buffer at $4^{\circ} \mathrm{C}$ or with testicular hyaluronidase (Wydase, Wyeth Laboratories, Inc., Div. of American Home Products, Inc., Philadelphia) at $37^{\circ} \mathrm{C}$ and were chromatographed on $0.9 \times 7.0$ Dowev $1 \times 2$ columns according to Calatroni and diFerrante (15).

The recovery of chondroitin-4 and $-6-\mathrm{SO}_{4}$ and of a mixture of hyaluronic acid, heparin- $\mathrm{SO}_{4}$, and dermatan-SO on Dowex $1 \times 2$ columns ranged from $89 \%$ to $97 \%$.

Electrophoresis. Samples were divided in two: one was incubated with hyaluronidase and the other in buffer. Both were precipitated in $71 \%$ ethanol. The precipitates were dissolved in $20 \mu \mathrm{l}$ water and applied to cellulose acetate membrane. Electrophoresis was performed in a Beckman microzonal apparatus (Beckman Instruments, Inc., Electronic Instruments Div., Schiller Park, Ill.) in $0.6 \mathrm{M}$ acetate-formate $\mathrm{pH} 2.55$ buffer at $5 \mathrm{~mA}$ for $30 \mathrm{~min}$. The membranes were stained for $8 \mathrm{~min}$ with $1 \%$ alcian blue in $1: 1$ ethanol/acetate $(\mathrm{pH} 5.8, \mathrm{I}=0.05)$.

\section{Analytical procedures}

Dialysis was performed in cellophane bags prepared according to Korn (20) by being heated in a dry oven at $65^{\circ} \mathrm{C}$ for 3 days. Hexuronic acid was determined by Galambos modification (14) of the carbozole reaction. The presence of sulfamate in this modification (14) permitted the reliable estimation of hexuronic acid in proteoglycans that produced considerable yellow-brown discoloration after the addition of carbazole in the absence of sulfamate. Even in the presence of sulfamate, slight orange discoloration developed in addition to the typical carbazole color in proteoglycan fractions with $\mathrm{pI}>3.1$. In these fractions hex- uronic acid was probably overestimated. Hexose was estimated by the anthrone procedure with galactose as standard (21), fucose according to Tsiganos and Muir (22), sialic acid by the resorcinol method (23), protein according to Lowry, Rosebrough, Farr, and Randall (24), and sulfate according to Muir (25). Hexosamines were determined after hydrolysis in $2.5 \mathrm{~N} \mathrm{HCl}$ at $100^{\circ} \mathrm{C}$ in vacuum-sealed ampules for $20 \mathrm{~h}$ (these conditions gave maximum recoveries). The tubes were dried three times in vacuum and the glucosamine and galactosamine were determined on a Beckman 120C automatic amino acid analyzer.

The amino acids were determined after hydrolysis in 6 $\mathrm{N} \mathrm{HCl}$ for $24 \mathrm{~h}$ at $100^{\circ} \mathrm{C}$ in sealed tubes from which oxygen was removed to reduce excessive destruction of amino acids in the presence of carbohydrates. The tubes were dried in a vacuum three times and the amino acids were measured on a Beckman-120C automatic amino acid analyzer. No correction was made for the presence of carbohydrates.

\section{Criteria for identification}

Hyaluronic acid. (a) CPC precipitate was soluble in $0.35 \mathrm{~N} \mathrm{NaCl},(b)$ glucosamine was the amino sugar, (c) fraction contained no $\mathrm{SO}_{4},(d)$ elution pattern from Dowex $1 \times 2$ resin and electrophoretic mobility were similar to that of commercial hyaluronic acid, and $(e)$ it was susceptible to hydrolysis with testicular hyaluronidase. (Hyaluronic acid standards were from Nutritional Biochemicals Co., Cleveland, Ohio.)

Heparan $\mathrm{SO}_{4}$. (a) CPC precipitate was soluble in $0.6 \mathrm{~N}$ $\mathrm{NaCl},(b)$ glucosamine was the amino sugar, (c) the fraction contained $\mathrm{SO}_{4},(d)$ elution pattern from Dowex $1 \times 2$ resin and electrophoretic mobility were similar to those of purified heparan $\mathrm{SO}_{4},(e)$ the fraction resisted hydrolysis with testicular hyaluronidase. (Heparan $\mathrm{SO}_{4}$ standard was isolated from crude commercial product according to Linker and Hovingh [26]).

Chondroitin-6 and $-4-\mathrm{SO}_{4}$. (a) were not removed from their CPC precipitate with $0.6 \mathrm{~N} \mathrm{NaCl},(b)$ galactosamine was their amino sugar, (c) they contained $\mathrm{SO}_{4},(d)$ the elution pattern from Dowex $1 \times 2$ resin and electrophoretic mobility were the same as those of shark and bovine chondroitin-SO $\mathrm{SO}_{4},(e)$ they were susceptible to testicular hyaluronidase hydrolysis. It was assumed that the chondroitinSO, soluble in high concentrations of ethanol is predominantly chondroitin-6-SO, and that having low ethanol solubility is predominantly chondroitin-4-SO4.

Dermatan $\mathrm{SO}_{4}$ (a) was not removed from its CPC precipitate by $0.6 \mathrm{~N} \mathrm{NaCl}$, (b) galactosamine was the amino sugar, $(c)$ the precipitate contained $\mathrm{SO}_{c},(d)$ the elution pattern from Dowex $1 \times 2$ resin and electrophoretic mobility were similar to those of dermatan $\mathrm{SO}_{4},(e)$ the precipitate resisted hydrolysis by testicular hyaluronidase, and (f) was not soluble in $20 \%$ ethanol at $12^{\circ} \mathrm{C}$. (Dermatan SO, standard was a gift from Roger W. Jeanloz.)

On histologic sections collagen and alcian blue-reactive GAG were graded on $0-4$. The histologic gradings were correlated with biochemical estimates of collagen and GAG respectively.

\section{RESULTS}

\section{Collagen}

The total and $1 \mathrm{~N} \mathrm{NaCl}$-extractable collagen concentrations are described in Table II. Compared to normal 
TABLE II

Collagen Content of Normal Liver and in Alcoholic Liver Disease

\begin{tabular}{|c|c|c|c|}
\hline & $n$ & $\begin{array}{c}\text { Total } \\
\text { collagen } \ddagger\end{array}$ & $\begin{array}{c}\mathrm{N} \mathrm{NaCl}- \\
\text { extractable } \\
\text { collagen }\end{array}$ \\
\hline & & \multicolumn{2}{|c|}{$m g \mathrm{HO}-\mathrm{Pr} / \mathrm{g} \mathrm{POL}$} \\
\hline Normal & 10 & $6.9^{*} \pm 0.37$ & $0.13 \pm 0.06$ \\
\hline Fatty liver & 5 & $7.2 \pm 1.5$ & $0.4 \pm 0.12$ \\
\hline Alcoholic hepatitis & 7 & $28.1 \pm 3.1$ & $2.01 \pm 0.39$ \\
\hline Cirrhosis $\ddagger$ & 10 & $27.4 \pm 2.8$ & $1.09 \pm 0.21$ \\
\hline
\end{tabular}

The data presented in this Table and in Table III are means $\pm \mathrm{SE}$ of each diagnostic group. The average estimate of replicate analyses per liver was used to compute the mean per group. The number of livers in each group and not the number of samples analyzed per liver was used as " $n$ " and df in statistical computations.

$n$, number of livers per diagnostic category.

$*$ Mean $\pm \mathrm{SE}$ of livers per diagnostic catogory.

$\ddagger$ All visible fibrous scar tissue was excluded.

liver, total or neutral salt-soluble collagen concentration in fatty livers was not different $(P>0.1)$; however, both were increased in alcoholic hepatitis and in cirrhosis $(P<0.001)$. Total collagen concentration was the same in alcoholic hepatitis and cirrhosis, but the concentration of $1 \mathrm{~N} \mathrm{NaCl}$-extractable collagen in alcoholic hepatitis was almost twice that found in cirrhosis $(P=0.06)$.

\section{GAG and proteoglycans}

The total, extractable, and nonextractable G.tG are described in Table III.

\section{Extractable GAG (proteoglycans)}

Fig. 1 describes the distribution of proteoglycans according to their pI. Duplicates were within $\pm 10 \%$ of the average. The distribution pattern (percent of total in each fraction) of proteoglycans was similar in normal liver, fatty liver, and cirrhosis. The two fractions with pIs between 2 and 3.1 accounted for most of the increase of proteoglycans in livers with alcoholic hepatitis (Fig. 1 , Table IV, $P<0.01$ ). The proteoglycan content of cirrhotic livers in fractions with $\mathrm{pI} \leq 3.1$ appeared to be intermediate between that of alcoholic hepatitis and normal or fatty livers (Fig. 1). The data are insufficient to define precisely the probability of chance occurrence of the observations. As the $\mathrm{pI}$ increased above 3.1, in each fraction both the protein and the hexosamine-to-hexuronic acid ratios increased, and the hexosamines consisted exclusively of glucosamine (Table IV). These changes were due to increasing proportions of glycoproteins and decreasing glucosaminoglycuronans in fractions with increasing pI. Further analysis of these com-
TABLE III

Extractable (Proteoglycans) and Nonextractable GAG Hexuronic Acid

\begin{tabular}{|c|c|c|c|c|}
\hline & \multirow[b]{2}{*}{$\begin{array}{c}\text { Normal } \\
(n-10)\end{array}$} & \multicolumn{3}{|c|}{ Alcoholic } \\
\hline & & $\begin{array}{c}\text { Fatty } \\
(n-5)\end{array}$ & $\begin{array}{l}\text { Hepatitis } \\
\quad(n-7)\end{array}$ & $\begin{array}{c}\text { Cirrhosis } \\
(n-10)\end{array}$ \\
\hline & \multicolumn{4}{|c|}{$\mu g / 10 \mathrm{~g} D D L$} \\
\hline Extractable & $243^{*} \pm 5.5$ & $178 \pm 68$ & $744 \S \pm 151$ & $310 \pm 89$ \\
\hline Nonextractable & $325 \pm 61$ & $273 \pm 83$ & $492 \ddagger \pm 47$ & $713 \ddagger \pm 160$ \\
\hline Sum of means & 568 & 441 & 1236 & 1023 \\
\hline
\end{tabular}

The observed difference of extractable GAG between alcoholic hepatitis and cirrhosis was due to chance: $P<0.05$, and that of nonextractable GAG: $P=0.19$. $n$, number of livers per diagnostic category. See Note from Table II.

* Mean $\pm \mathrm{SE}$ of livers per diagnostic category.

$\ddagger P<0.05$.

$\S P<0.01$.

pounds has not been undertaken because sufficient material was not available for their identification. Furthermore, even the modified carbozole reaction (14) probably overestimated the hexuronic acid content in fractions with $\mathrm{pI}>3.1$. No hexuronic acid was detectable in fractions with $\mathrm{pI}>4.4$.

The proteoglycans with $\mathrm{pI} \leq 3.1$ contained neither sialic acid nor fucose.

\section{GAG in proteoglycans}

The elution pattern of GAG from Dowex $1 \times 2$ columns and the proportion of hyaluronidase-digestible GAG in each diagnostic category are illustrated in Fig. 2. The affinity to the resin for GAG from normal liver was lower (all were removed with $1.5 \mathrm{~N} \mathrm{NaCl}$ ) than those from fatty liver, alcoholic hepatitis, and cirrhosis, where all GAG were not removed even with $2 \mathrm{~N} \mathrm{NaCl}$. Each diagnostic category contained various proportions of the GAG removed at $0.1 \mathrm{~N} \mathrm{NaCl}$. These were small, dialyzable fragments of GAG precipitable in $70 \%$ etha-

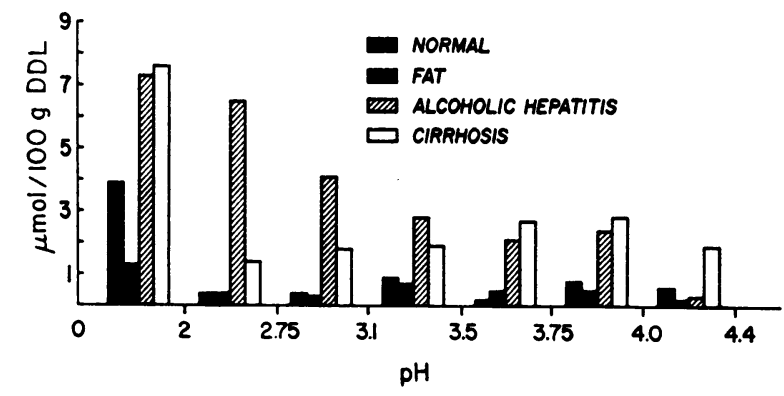

FIGURE 1 Extractable GAG (proteoglycans) (mean of replicates). The proteoglycans were electrophoresed in a continuous sucrose gradient in an electrofocusing column. After equilibrium was reached, the compounds were eluted according to their $\mathrm{pI}$. The fractions with $\mathrm{pI}>3.1$ contained increasing proportions of glycoproteins. 
TABLE IV

Distribution of Protein, Hexuronic Acid, Glucosamine in Extractable GAG (Proteoglycans)

Excluded from Sephadex G-150 (means of duplicates)

\begin{tabular}{|c|c|c|c|c|c|c|c|c|c|c|c|c|}
\hline \multirow[b]{3}{*}{$\mathrm{pI}$} & \multirow{2}{*}{\multicolumn{3}{|c|}{ Normal }} & \multirow{2}{*}{\multicolumn{6}{|c|}{ Alcoholic }} & \multirow{2}{*}{\multicolumn{3}{|c|}{ Cirrhosis }} \\
\hline & & & & & & & & & & & & \\
\hline & Protein & $\begin{array}{l}\text { Hexu- } \\
\text { ronic } \\
\text { acid }\end{array}$ & $\begin{array}{l}\text { Glucos- } \\
\text { amine } \\
*\end{array}$ & Protein & $\begin{array}{l}\text { Hexu- } \\
\text { ronic } \\
\text { acid }\end{array}$ & $\begin{array}{l}\text { Glucos- } \\
\text { amine }\end{array}$ & Protein & $\begin{array}{l}\text { Hexu- } \\
\text { ronic } \\
\text { acid }\end{array}$ & $\begin{array}{l}\text { Glucos- } \\
\text { amine }\end{array}$ & Protein & $\begin{array}{l}\text { Hexu- } \\
\text { ronic } \\
\text { acid }\end{array}$ & $\begin{array}{l}\text { Glucos- } \\
\text { amine }\end{array}$ \\
\hline & \multicolumn{2}{|c|}{$\mu g / a l i q u o t$} & $\%$ & \multicolumn{2}{|c|}{ $\mu g /$ aliquot } & $\%$ & \multicolumn{2}{|c|}{$\mu g /$ aliquot } & $\%$ & \multicolumn{2}{|c|}{$\mu g /$ aliquot } & $\%$ \\
\hline$<2$ & 110 & 77 & $57 \ddagger$ & 141 & 25 & $73 \ddagger$ & 41 & 141 & $57 \ddagger$ & 73 & 148 & $75 t$ \\
\hline $2-2.75$ & 10 & 8 & $66 \ddagger$ & 6 & 8 & - & 27 & 125 & $66 t$ & 11 & 27 & $56 t$ \\
\hline $2.76-3.1$ & 10 & 7 & 67 & 5 & 6 & - & 19 & 80 & $90^{\circ}$ & 4 & 33 & - \\
\hline $3.11-3.5$ & 22 & 15 & 100 & 15 & 13 & 100 & 12 & 55 & 100 & 11 & 36 & 100 \\
\hline $3.51-3.75$ & 49 & 4 & 100 & 44 & 10 & 100 & 31 & 41 & 100 & 21 & 52 & 100 \\
\hline $3.76-4.0$ & 53 & 16 & 100 & 97 & 10 & 100 & 47 & 47 & 100 & 31 & 54 & 100 \\
\hline $4.01-4.4$ & 76 & 12 & - & 23 & 3 & - & 24 & 6 & - & 46 & 36 & 100 \\
\hline
\end{tabular}

* Percent of total hexosamine as glucosamine.

$\ddagger$ The hexuronic acid: hexosamine ratio was approximately unity in fractions $\mathrm{pI} \leqslant 2.75$.

-, data are not available.

nol. These short GAG fragments represented in normal livers $55 \%$, in fatty livers $15 \%$, in alcoholic hepatitis $17 \%$, and in cirrhosis $20 \%$ of total GAG. The composition of remaining GAG was in normal liver, $28 \%$ was heparan $\mathrm{SO}_{4}$ and dermatan-SO4, and $17 \%$ was chondroitin-4 or $-6-\mathrm{SO}_{4}$; in alcoholic fatty liver, $85 \%$ was chondroitin-4 or $-6-\mathrm{SO}_{4}$; in alcoholic hepatitis, $27 \%$ was chondroitin-4 or $-6-\mathrm{SO}_{4}$, and $56 \%$ was heparan-SO4 and dermatan-SO4; and in cirrhosis, $80 \%$ was chondroitin- 4 or $-6-\mathrm{SO}_{4}$.
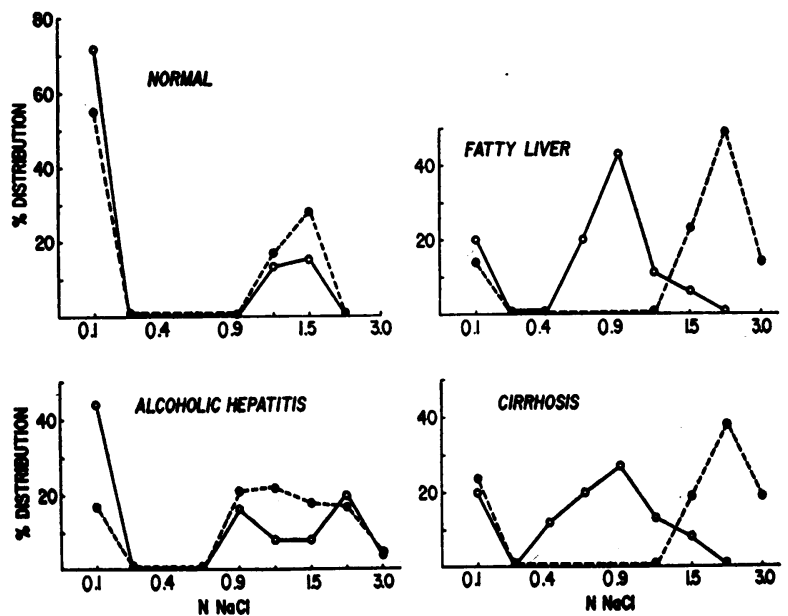

Figure 2 Extractable GAG, Mean of duplicates. The GAG were isolated from proteoglycans. Duplicates were eluted from $0.9 \times 7 \mathrm{~cm}$ Dowex $1 \times 2$ columns with increasing $\mathrm{NaCl}$ concentrations $\left(\mathrm{O}_{---} \mathrm{O}\right.$ ). Duplicates were incubated with hyaluronidase and were chromatographed in the same manner. ( $\mathrm{O}-\mathrm{O})$ The hyaluronidase-susceptible GAG were hydrolyzed and the smaller fragments were eluted by lower $\mathrm{NaCl}$ concentrations. Therefore, a shift to the left indicates hydrolyzed GAG.
The amino acid composition of pooled extractable proteoglycans with $\mathrm{pI} \leq 3.1$ from normal livers was similar to that from alcoholic hepatitis. The amino acid composition of proteoglycans extracted from livers was similar to that of cartilage $(27,28)$. The most common amino acids were aspartic acid, glutamic acid, glycine, serine, and proline (Table V).

Peak II. A fraction of the extractable GAG was retained on Sephadex G-150 in 6 of 10 normal livers (average of $29 \%$ ) and in 4 of 10 cirrhotic livers (average of $18 \%$ ). The retention of extractable GAG on the Sephadex G-150 gel indicates smaller molecular size. The most likely explanation for Peak II is antemortem anoxia which probably reduced hepatic $\mathrm{pH}$ to levels where lysosomal enzymes hydrolyzed detectable amounts of GAG from proteoglycans $(27,28)$.

The GAG in Peak II from normal livers were dermatan-SO, and heparan-SO, and from cirrhotic were chondroitin-4 or $-6-\mathrm{SO}_{4}(52 \%)$, and dermatan-SO، $(48 \%)$.

\section{Nonextractable GAG}

The isolated GAG contained up to $3 \%$ protein (assuming that hexuronic acid was $30 \%$ of molecular weight) but no trend was detectable in the GAG fractions or disease categories. Neither sialic acid nor fucose was detectable in any of the GAG fractions.

The total nonextractable GAG are described in Table III and Fig. 3. Both alcoholic hepatitis and cirrhosis contained more GAG than normal or fatty livers $(P<$ $0.05)$. However, the GAG content in normal livers was similar to that in fatty livers, and in alcoholic hepatitis it was not different from that in cirrhosis $(P=0.19)$. The composition of each of the GAG fractions described 
in Fig. 3 was not affected by diagnostic categories. (The variations between diagnostic categories of the same GAG fraction were not significantly greater than variations of duplicates of the fraction of the same diagnostic category.)

Fraction $A$ contained both hyaluronidase-susceptible and -resistant GAG. Hexosamine composition was $95 \%$ glucosamine and $5 \%$ galactosamine. On electrophoresis the major band was indistinguishable from hyaluronic acid. Two smaller bands accounted for approximately half of this fraction and both were resistant to hyaluronidase: one migrated with hyaluronic acid, the other one moved faster and was indistinguishable from heparanSO, One or both of these unknown fractions contained $\mathrm{SO}_{4}$.

Fraction $B$ consisted of two-thirds heparan-SO, and one-third was susceptible to hyaluronidase digestion. Approximately $88 \%$ of the latter was hyaluronic acid and approximately $12 \%$ of this fraction was galactosaminoglycuronan, such as chondroitin or chondroitin-SO4.

Fractions $C, D$ and $E$ were chondroitin- 6 and $-4-\mathrm{SO}_{4}$.

Fraction $F$ was mostly dermatan-SO $\mathrm{SO}_{4}$ less than a fourth was hyaluronidase-susceptible chondroitin-4-SO 4

Fraction $G$ was chondroitin-6-SO $\mathrm{SO}_{4}$ and probably contained keratan-SO, but the latter was not further identified.

Normal. The dominant GAG were chondroitin-SO, mostly chondroitin-6-SO4. The dermatan- $\mathrm{SO}_{4}$ and heparan-SO, contents of normal livers was not significantly different from those of livers with alcoholic liver damage.

Alcoholic fatty liver. Most of the GAG were chondroitin-SO4s.

Alcoholic hepatitis liver. It contained more hyaluronic acid (Fraction $A$ ) than normal, fatty, or cirrhotic livers $(P<0.01)$. The dominant GAG were chondroitin-SO4s.

Cirrhosis. Over $81 \%$ of GAG was in Fraction D and over $91 \%$ of GAG were chondroitin-SO4s.

Histologic examinations showed many more fibers in groups of livers with high collagen content (alcoholic hepatitis and cirrhotic) than in normal or fatty livers, confirming previous observations (29). However, no correlation was demonstrable between chemically measured collagen concentration and histological estimates of fibrosis within the high collagen groups (alcoholic hepatitis or cirrhosis) or within the low collagen (fatty or normal) livers. Similarly, histologic estimates of GAG clearly separated the groups of livers with high GAG content (alcoholic hepatitis and cirrhosis) from normal and fatty livers. There was no definite correlation between alcian blue-reactive ground substance and chemically estimated GAG within the alcoholic hepatitis and cirrhosis groups. In normal or fatty livers alcian blue did not stain extracellular GAG outside blood vessel walls.
TABLE V

Amino Acid Composition of Proteoglycuns

\begin{tabular}{lc}
\hline & \multicolumn{1}{c}{ Range* } \\
\hline & $\mu$ mol $/ 100 \mu$ mol \\
Aspartic & $105-129$ \\
Threonine & $52-65$ \\
Serine & $127-147$ \\
Glutamic acid & $155-179$ \\
Proline & $71-79$ \\
Glycine & $140-149$ \\
Alanine & $52-61$ \\
Valine & $54-66$ \\
I.eucine & $41-54$ \\
\hline
\end{tabular}

* The range of duplicate analyses of the nine most common amino acids from normal and from alcoholic hepatitis livers.

\section{DISCUSSION}

The acetone-ether treatment of each noncirrhotic liver yielded a homogeneous powdery material. Cirrhotic livers, however, had readily recognizable tough fibrous fragments, presumably scar tissue, mixed with the homogeneous but granular DDL. Although intralobular and periportal fibrosis were seen in alcoholic hepatitis on histologic examinations, even in these livers the DDL was homogeneous and powdery. It is reasonable to assume that the homogeneous DDL represented hepatic parenchyma with its connective tissue framework.

The HO-Pr concentrations of selected fibrous fragments from cirrhotic livers were two-to-threefold higher than that of the homogeneous DDL from which visible fibrous pieces were removed. The HO-Pr concentrations of these fibrous scar fragments were between $4 \%$

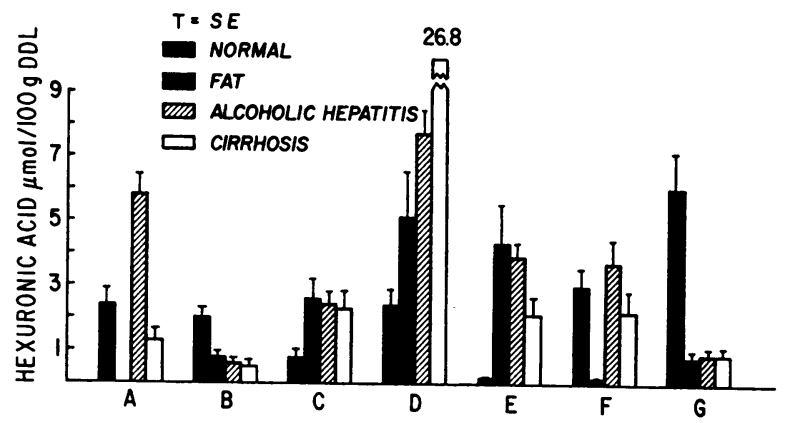

Figlre 3 Nonextractable GAG, Mean \pm SE per diagnostic category. (Number of cases per category: see Table III.) The composition of each fraction is described in the text. The dominant GAG in each fraction were: Fraction $A$, hyaluronic acid; Fraction $\mathrm{B}$, heparan- $\mathrm{SO}_{4}$; Fraction $\mathrm{C}$, chondroitin-6-SO $\mathrm{SO}_{4}$; Fraction $\mathrm{D}$, chondroitin-6 and -4-SO

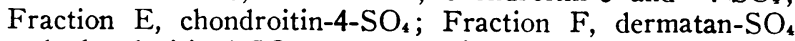
and chondroitin-4-SO $\mathrm{S}_{4}$; and Fraction G, chondroitin-6-SO, (contained also keratan-SO4). 
and $9 \%$, as compared to $13.6 \%$ found in our collagen standard. Because inadvertent and arbitrary variations of the proportions of these fibrous fragments in DDL would have significantly affected the apparent collagen concentrations of cirrhotic livers, all visible fibrous fragments were removed from DDL before HO-Pr contents were estimated. Consequently, only the homogeneous, granular DDL was studied in cirrhotic livers. This probably represented the connective tissue of regenerative nodules and those portions of the septa easily fragmented during homogenization in acetone.

Our observations are in accord with those of Kent, Fels, Dubin, and Popper (29), who found that the total $\mathrm{HO}-\mathrm{Pr}$ concentration in cirrhotic livers was four times that of normal livers and that the collagen content of livers with alcoholic hepatitis " was similar to that of Laennec's cirrhosis.

The insoluble and soluble collagen contents of normal livers were not significantly different from that of alcoholic fatty livers; however, the content of both types of collagen was significantly greater in alcoholic hepatitis and in cirrhosis. Our data do not provide kinetic information about the turnover rate of hepatic collagen. Nevertheless, it is generally accepted that neutral salt-soluble collagen is composed of young, recently synthesized fibrils (30). The large increase of young collagen content in alcoholic hepatitis and alcoholic cirrhosis is compatible with active fibrillogenesis.

The large increase of extractable GAG macromolecules and the increase of soluble collagen content in alcoholic hepatitis but not in fatty livers support the suggestion of increased fibroblast activity in alcoholic hepatitis. These data provide important support to clinical observations that suggested that alcoholic hepatitis is, but fatty liver is not, a stage in the pathogenesis of alcoholic liver disease to cirrhosis (31).

For GAG analyses over 1,000-fold larger amounts of DDL were used than for the estimation of collagen content. In the study of hepatic GAG content, therefore, a significant error was avoided by not removing visible fibrous fragments from cirrhotic DDL, as either the entire specimen or a very large proportion of the liver powder was used. Therefore the original proportions of liver powder and scar tissue were maintained in each specimen.

However, all visible vascular tissue was removed from each liver because of its high content of chondroitin- $\mathrm{SO}_{4} \mathrm{~S}$ and heparan-SO 4 which could have significantly affected the apparent extravascular hepatic GAG.

- The term "alcoholic hepatitis" was introduced in 1961. In the 1950's a variety of terms were used to describe this lesion. These authors (29) called alcoholic hepatitis "early diffuse septal cirrhosis with fat."
The composition of increased GAG in the ground substance in alcoholic hepatitis shows similarities to that found in early scar formation. It has been shown that hyaluronic acid concentration increases rapidly in the ground substance during the early stage of wound healing (32). The increase of hyaluronic acid both in the extractable and the nonextractable GAG of alcoholic hepatitis is responsible in part for the increased GAG content in these livers. Hyaluronic acid accounted for about $75 \%$ of the increased proteoglycans with pI $>2$, $<3.1$ (Fig. 1, Table IV), and of $50 \%$ of the increased Fraction $A$ in the nonextractable GAG (Fig. 3).

The most common GAG in the cirrhotic liver were the chondroitin-SO $\mathrm{SO}_{4} \mathrm{~S}$, which accounted for over $90 \%$ of the nonextractable molecules. In the cirrhotic liver most of the GAG was bound firmly to insoluble collagen fibers, in contrast to that found in alcoholic hepatitis. This indicates a more mature fibrous organization in the cirrhotic liver.

The statistical significance of the increase of extractable GAG with $\mathrm{pI}<2$ in cirrhotic livers over that in fatty or normal livers could not be documented because of the unavailability of enough material to permit the estimation of these compounds in individual livers to provide adequate data for statistical analysis. Nevertheless, the extractable GAG in cirrhotic livers with $\mathrm{pI}<2$ were similar to that of alcoholic hepatitis (Fig. 1).

Proteoglycans are the native state of GAG in connective tissue. These compounds were shown to be essential for the formation of collagen fibrils from newly secreted tropocollagen and also for the organization of mature collagen fibers. Fiber formation seems to be accelerated by large aggregates of proteoglycans. These aggregates consist of complexes of proteoglycans and glycoproteins. There seems to be little doubt that the proteoglycans function as extracellular assembly and architecture of collagen during fibrogenesis in vivo (33, $6)$. On the basis of physicochemical and electronmicroscopic observation it seems probable that GAG are firmly bound to collagen in fibrous connective tissues (34-36).

The amino acid composition of the protein moiety and the carbohydrate chains of proteoglycans in the liver were similar to that found in other tissues. It is reasonable to assume that the process of scar formation and fibrosis in the liver is not unique but is similar to that found elsewhere in the body. Therefore, it is likely that the GAG in the hepatic connective tissue also play an important role in the rate of formation, orientation, and cross-linking of collagen fibrils, and promote the formation of fibrous collagen bundles. In that case it is probable that the GAG of the ground substance could play a deciding role in the conversion 
of the early and apparently reversible stage of fiber formation into the mature and apparently irreversible stage of hepatic fibrosis.

It has been shown that the hepatic lysosomes contain a hydrolytic enzyme that has substrate specificity similar to testicular hyaluronidase (7). It was suggested that the increase of GAG in cirrhotic livers is due to the accumulation of hepatic hyaluronidase-resistant GAG such as dermatan-SO (37). However, in alcoholic hepatitis and in cirrhosis, the increased GAG were not due to hyaluronidase-resistant GAG. Furthermore, even normal livers had high dermatan-SO and heparan-SO content, as was also noted by Delbruck (38). We could not demonstrate an increase of these GAG in cirrhosis. It is probable that the accumulation of large amounts of GAG in alcoholic hepatitis and cirrhosis was due to increased rate of production rather than decreased rate of destruction of GAG. In order to confirm this suggestion, additional studies are required to directly measure the kinetics of GAG metabolism or estimate hyaluronidase-like activity in the immediate vicinity of GAG in hepatic connective tissue. These studies will require patients, because in exprimental alcoholic or toxic liver injury, neither alcoholic hepatitis nor increased accumulation of GAG were demonstrable.

The finding of increased content of both young collagen and GAG suggests persistence of fibroblast activity in cirrhotic livers. Yet these livers showed only minimal parenchymal necrosis and no PMN-leukocytic inflammatory exudate on hematoxylin-eosin-stained sections. Continued active fibrosis is compatible with the observations that demonstrated the transformation of the micronodular (Laennec's) cirrhosis to a macronodular (postnecrotic-type) cirrhosis $(39,40)$. This type of transformation was observed in those cirrhotic patients who stopped drinking and in whom alcoholic hepatitis subsided. Indeed, serial biopsies in patients with alcoholic hepatitis showed the development of cirrhosis even in those who stopped drinking and in whom the acute alcoholic hepatitis subsided (31).

It seems reasonable to postulate that some unknown mechanism can "induce" hepatic fibroblasts during alcoholic hepatitis. These affected fibroblasts may continue to remain active even after the injurious agent, i.e. ethanol, has been withdrawn and active parenchymal necrosis and PMN-leukocytic inflammation have subsided. The persistence of hepatic fibroblast activity was associated with ductular proliferation and with the prominence of mononuclear cells (31). Further observations are required to document whether one or more of the mononuclear cell types is responsible for continued activity of hepatic fibroblasts after the acute parenchymal injury.

\section{ACKNOWLEDGMENTS}

This study was supported in part by L. S. P. H. S. Grant No $\mathrm{MH} 17075$.

\section{REFERENCES}

1. Alcohol and the Liver. 1971. W. Gerok, K. Sickinger, and H. H. Hannekeuser, editors. Friedrich-Karl Schattauer-Verlag, Stuttgart.

2. Galambos, J. T. 1972. Alcoholic hepatitis: its therapy and prognosis. Prog. Liver Dis. 4: 567.

3. Demoise, C. F., J. T. Galambos, and A. Falek. 1971. Tissue culture of adult human liver. Gastroenterology. $60: 390$.

4. Feinman, L., and C. S. Lieber. 1972. Hepatic collagen metabolism: effect of alcohol consumption in rats and baboons. Science (Wash., D. C.). 176: 795.

5. Popper, H., and S. Udenfriend. 1970. Hepatic fibrosis. Correlation of biochemical and morphologic investigations. Am. J. $M_{c d}$. $49: 707$.

6. Meyer, K. 1969. Biochemistry and biology of mucopolysaccharides. Am. J. Med. 47: 664 .

7. Hutterer, F. 1966. Degradation of mucopolysaccharides by hepatic lysosomes. Biochim. Biophys. Acta. 115: 312.

8. Lischner, M. W., J. F. Alexander, and J. T. Galambos. 1971. Natural history of alcoholic hepatitis. I. The acute disease. Am. J. Dig. Dis. 16: 481.

9. Rappaport, A. M. 1969. Anatomic considerations. In Diseases of the Liver. L. Schiff, editor. J. B. Lippincott Co., Philadelphia. 3rd edition. 1.

10. Bornstein, P., and K. A. Piez. 1964. A biochemical study of human skin collagen and the relation between intra- and intermolecular cross-linking. J. Clin. Invest. 43: 1813.

11. Bergman, I., and R. Loxley. 1969. Lung tissue hydrolysates: studies of the optimum conditions for the spectrophotometric determination of hydroxyproline. Analyst (Amsterdam) . $94: 575$.

12. Bergman, I., and R. Loxley. 1970. The determination of hydroxyproline in urine hydrolysates. Clin. Chim. Acta. $27: 347$.

13. Mashburn, T. A., Jr., and P. Hoffman. 1966. Preparative continuous-flow electrophoresis of acidic mucopolysaccharides. Analyt. Biochem. 16: 267.

14. Galambos, J. T. 1967. The reaction of carbazole with carbohydrates. I. Effect of borate and sulfamate on the carbazole color of sugars. Analyt. Biochem. 19: 119.

15. Calatroni, A., and N. diFerrante. 1969. The glycosaminoglycans of human term placenta. Carbohydr. Res. 10: 535.

16. Malawista, I., and M. Schubert. 1958. Chondromucoprotein: New extraction method and alkaline degradation. J. Biol. Chem. 230: 535.

17. Heinegard, D., and S. Gardell. 1967. Studies on proteinpolysaccharide complex (proteoglycan) from human nucleus pulposus. I. Isolation and preliminary characterisation. Biochim. Biophys. Acta. 148: 164.

18. Hoffman, P., and T. A. Mashburn, Jr. 1967. Proteinpolysaccharide of bovine cartilage. J. Biol. Chem. 242: 3799.

19. Meyer, K., A. Linker, E. A. Davidson, and B. Weissmann. 1953. The mucopolysaccharides of bovine cornea. J. Biol. Chem. 205 : 611.

20. Korn, E. D. 1959. Isolation of heparin from mouse mast cell tumor. J. Biol. Chem. 234: 1325. 
21. Hodge, J. E., and B. T. Hofreiter. 1962. Determination of reducing sugars and carbohydrates. In Methods Carbohyd. Chem. 1: 380.

22. Tsiganos, C. P., and H. Muir. 1966. Estimation of pentoses and methylpentoses in biopolymers, in particular of fucose and xylose. Anal. Biochem. 17: 495.

23. Whitehouse, M. W., and F. Zilliken. 1960. Isolation and determination of neuraminic (sialiac) acids. Methods Biochem. Anal. 8: 199.

24. Lowry, O. H., N. J. Rosebrough, A. L. Farr, and R. J. Randall. 1951. Protein measurement with the folin phenol reagent. J. Biol. Chem. 193: 265.

25. Muir, H. 1958. The nature of the link between protein and carbohydrate of a chondroitin sulphate complex from hyaline cartilage. Biochem. J. 69: 195.

26. Linker, A., and P. Hovingh. 1968. The enzymatic degradation of heparitin sulfate. II. Isolation and characterization of nonsulfated oligosaccharides. Biochim. Biophys. Acta. 165: 89.

27. Hascall, V. C., and S. W. Sajdera. 1970. Physical properties and polydispersity of proteoglycan from bovine nasal cartilage. J. Biol. Chem. 245: 4920.

28. Scheinthal, B. M., and M. Schubert. 1963. Fractionation of the degradation products of compounds of protein and polysaccharide from cartilage. J. Biol. Chem. 238: 1935.

29. Kent, G., I. G. Fels, A. Dubin, and H. Popper. 1959. Collagen content based on hydroxyproline determinations in human and rat livers. Lab. Invest. 8: 48.

30. Gallop, P. M., O. O. Blumenfeld, and S. Seifter. 1972. Structure and metabolism of connective tissue proteins. Annu. Rev. Biochem. 41 : 617.
31. Galambos, J. T. 1972. Natural history of alcoholic hepatitis. III. Histological changes. Gastroenterology. 63: 1026.

32. Dorner, R. W. 1968. Changes in glycosaminoglycan composition associated with maturation of regenerating rabbit tendon. Arch. Biochem. Biophys. 128: 34.

33. Lowther, D. A., and M. Natarajan. 1972. The influence of glycoprotein on collagen fibril formation in the presence of chondroitin sulphate proteoglycan. Biochem. J. $127: 607$

34. Serafini-Fracassini, A., and J. W. Smith. 1966. Observations on the morphology of the proteinpolysaccharide complex of bovine nasal cartilage and its relationship to collagen. Proc. R. Soc. Lond. B. Biol. Sci. $165: 440$.

35. Schubert, M, 1966. Structure of connective tissues, a chemical point of view. Fed. Proc. 25: 1047.

36. Toole, B. P., and D. A. Lowther. 1968. Dermatan sulfate-protein: isolation from and interaction with collagen. Arch. Biochem. Biophys. 128: 567.

37. Huttered, F., and P. Bacchin. 1968. Mucopolysaccharides in normal and cirrhotic liver in man. Fed. Proc. $27: 412$.

38. Delbruck, V. A. 1968. Säure Glycosaminoglycane des normalen und cirrhotischen Leberbindegewebes vom Menschen. Z. Klin. Chem. Klin. Biochem. 6: 460.

39. Rubin, E., S. Krus, and H. Popper. 1962. Pathogenesis of postnecrotic cirrhosis in alcoholics. Arch. Pathol. 73 : 288.

40. Hargrove, M. D., Jr., J. T. Galambos, and T. D. Raaen. 1962. Relationship between alcoholism and morphogenesis of cirrhosis. South. Med. J. 55: 483. 